\title{
Evolution of tobacco products: recent history and future directions
}

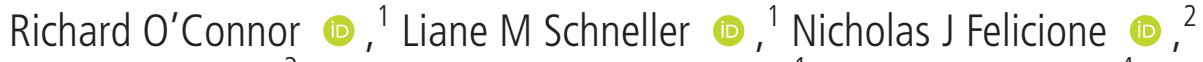 \\ Reinskje Talhout, ${ }^{3}$ Maciej Lukasz Goniewicz 다, ' David L Ashley (i) ${ }^{4}$
}

${ }^{1}$ Department of Health Behavior, Roswell Park Cancer Institute, Buffalo, New York, USA

${ }^{2}$ Health Behavior, Roswell Park Comprehensive Cancer Center, Buffalo, New York, USA

${ }^{3}$ National Institute for Public Health and the Environment (RIVM), Bilthoven, The Netherlands

${ }^{4}$ School of Public Health, Georgia State University, Atlanta, Georgia, USA

\section{Correspondence to}

Professor Richard O'Connor, Department of Health Behavior, Roswell Park Cancer Institute, Buffalo, NY 14203, USA; richard.o'connor@roswellpark. org

Received 30 June 2021 Accepted 4 November 2021

\section{ABSTRACT}

Declines in cigarette smoking prevalence in many countries and the consolidation of the tobacco industry have prompted the introduction of other forms of nicotine delivery. These include electronic nicotine delivery systems (ENDS), heated tobacco products (HTPS) and oral nicotine products (ONPs). Evolving over time, some of these products now deliver nicotine at levels comparable to cigarettes and may serve as effective substitutes for smokers. However, certain products, especially ENDS like JUUL, have also appealed to youth and non-smokers, prompting concerns about expanding nicotine use (and potentially nicotine addiction). The tobacco industry could shift away from primarily promoting cigarettes to promoting ENDS, HTPs and/or ONPs, though at this time it continues to heavily promote cigarettes in low and middle-income countries. Differing regulatory regimes may place upward and downward pressures on both cigarettes and these newer products in terms of population use, and may ultimately drive the extent to which cigarettes are or are not displaced by ENDS, HTPs and/or ONPs in the coming decade.

\section{INTRODUCTION}

Current tobacco use has been declining globally, with $23.5 \%$ of adults currently using tobacco in 2018 , down from 33\% in 2000. About one-fifth $(20.9 \%)$ are expected to be tobacco users by $2025{ }^{1}$ Over $80 \%$ of tobacco users are cigarette smokers, ${ }^{1}$ making cigarettes the primary mode of tobacco consumption, though a diverse range of other combustible and non-combustible products (eg, snuff, chewing tobacco, cigars, waterpipe, pipes, bidis, kreteks) is available. Contemporaneous with, and potentially driven by, ${ }^{2}$ these declines in cigarette smoking is consolidation of the tobacco industry into a handful of global players-Philip Morris International (PMI), British American Tobacco (BAT), Japan Tobacco International (JTI) — and the introduction and marketing of other forms of nicotine delivery.

\section{BRIEF HISTORY OF TOBACCO PRODUCT INNOVATION}

The global declines in smoking present challenges to cigarette manufacturers, which have tried to adjust by developing or purchasing alternative products (smokeless, heated tobacco products (HTP), e-cigarettes) to which they can attempt to migrate their customers. These efforts, arrayed as a timeline in figure 1 , have met with a range of success and failure.

\section{Electronic nicotine delivery systems}

In 2007, a new type of product was launched for sale-electronic nicotine delivery systems (ENDS) (also called e-cigarettes or vaping products) — a class of products that commonly contain a battery that powers a heating element to aerosolise a liquid typically containing nicotine, flavourings and humectants. ${ }^{3}$ These products have changed substantially over the past decade, starting with disposable cigalikes that resembled a cigarette, then rechargeable devices with refillable tanks and more modifiability (eg, adjustable power) and, more recently, pod-style devices like JUUL. Originally marketed by Ruyan (later NJOY), the initial offerings were slow to capture market share, but interest in ENDS rose with the marketing of blu in $2009 .{ }^{4-8}$ JUUL launched in 2015 and quickly became the predominant ENDS brand in the USA. In 2019, Altria purchased a stake in JUUL. ${ }^{9}{ }^{10}$ ENDS are now the second most common tobacco product in the USA, with $4.5 \%$ of adults reporting current use. ${ }^{11}$ Similar prevalence has been observed in Europe, though regional differences exist, such as higher prevalence in Eastern than Western Europe. ${ }^{12}$ ENDS use is less common in Asia than in these other regions, with current use around $1.8 \%$ in China. ${ }^{13}$ ENDS also have emerged in South African market. ${ }^{14-16}$ ENDS use prevalence is even lower in some low and middle-income countries (LMICs) such as Bangladesh and Zambia. ${ }^{17}$ WHO recommends that ENDS be regulated to bar unproven health claims, minimise health risks, protect non-users from secondhand exposure and prevent initiation among youth (eg, by limiting advertising/sponsorship, restricting flavours), though the legal and regulatory status of these products differs widely by country. At present, 32 countries have barred the sale of ENDS, and a further 79 have enacted at least one regulation (such as use in public places, restrict advertising or include health warnings). ${ }^{18}$ For example, nonprescription ENDS with nicotine are illegal in India, Japan, Chile, Australia, among other countries. In the European Union (EU), the Tobacco Products Directive regulates the nicotine concentration (20 $\mathrm{mg} / \mathrm{mL}$ maximum), liquid container volume and packaging and labelling requirements of ENDS. ${ }^{19}$ In the USA, ENDS manufacturers were required to submit premarket tobacco applications in 2020, which the Food and Drug Administration (FDA) will evaluate and use to decide whether specific vaping products should remain on the market or be removed. Publicity surrounding JUUL's appeal to youth coupled with rising youth ENDS use in the USA has led to federal, state and local restrictions 


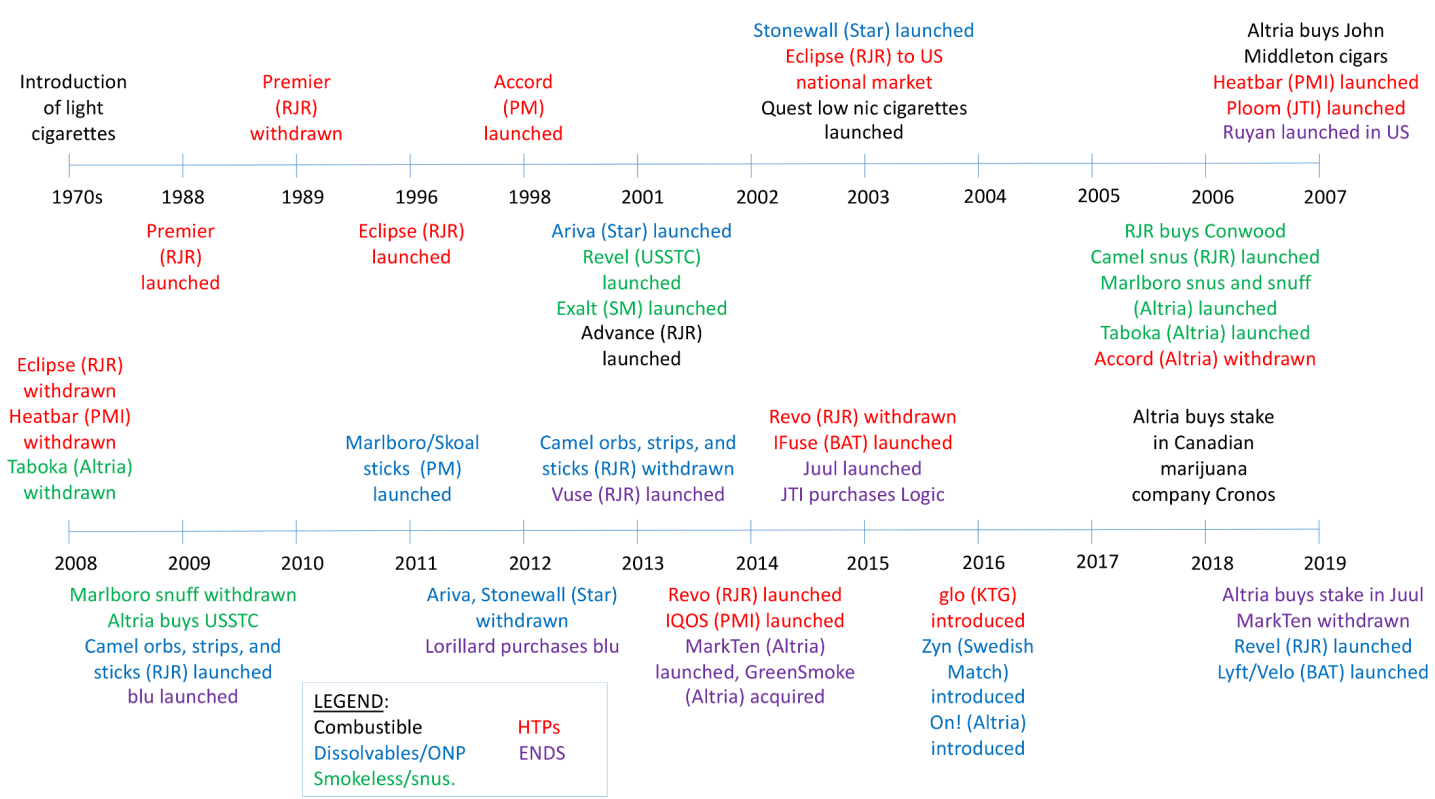

Figure 1 Timeline of new product introductions by the tobacco industry, 1970-2019. BAT, British American Tobacco; ENDS, electronic nicotine delivery systems; HTP, heated tobacco product; JTI, Japan Tobacco International; ONP, oral nicotine product; PM, Philip Morris; PMI, Philip Morris International; RJR, RJ Reynolds; SM, Swedish Match; USSTC, US Smokeless Tobacco Company.

on the sale of flavoured ENDS that appear to have reduced JUUL's overall market share and opened the door for competing products such as Puff Bar. Better monitoring of the market for these newer products is needed for tracking the industry's strategy of substituting use of these products in place of tobacco product use cessation.

\section{Heated tobacco products}

The class of HTPs, which generally heat tobacco to temperatures below combustion to generate a nicotine-containing aerosol, dates back to the introduction of Premier by RJ Reynolds (RJR) in $1988 .{ }^{20}$ Lighting the charcoal tip generated heat which, when passing down the rod, formed an aerosol that released flavour and nicotine from flavour beads and a small amount of tobacco. Premier was a market failure and was withdrawn from the market in $1989 .{ }^{21}$ Eclipse, ${ }^{22}$ a redesign of Premier, emerged in 1996. Accord, marketed by Philip Morris (PM) in 1998, was a new design with an external heat source into which the user inserted small cigarettes with a specially formulated reconstituted tobacco mix..$^{23}$ These two approaches to HTP technology, charcoal tip and external heat source, would serve as the basic designs for Revo, ${ }^{24}$ launched by RJR in 2014 and withdrawn in 2015; Heatbar, ${ }^{25}$ introduced by PM in 2007 and withdrawn in 2008. These early models were withdrawn from the market within a few years of their introduction. ${ }^{26}$ In more recent years, newer HTPs were met with greater receptivity among smokers, such that JTI's Ploom (launched in 2007), Philip Morris International (PMI)'s IQOS ${ }^{27}$ (launched internationally in 2014 and in the USA by Altria in 2020), BAT's iFuse (launched in 2015) and KTG's glo (launched in 2016) have been able to capture a substantial global market, primarily in the WHO Western Pacific Region. $^{28} 29$ Generally, HTPs are most popular in some Asian countries, followed by parts of Europe, USA and other regions. Current HTP use rose in Japan from 0.2\% in 2015 to 10\%-15\% in $2019,{ }^{30-32}$ and $4.4 \%$ of adults in Korea currently use an HTP. ${ }^{33}$ Prevalence has been lower across European countries (eg, $0.1 \%$ current users in 2016-2018), ${ }^{34}$ but seems to be increasing in select markets (eg, 1.1\%-Italy $2019^{35} ; 1.2 \%$-England ${ }^{36}$ ).
Current use prevalence was below $1 \%$ in other countries such as the USA, Canada and Australia, ${ }^{36}$ though other estimates demonstrated current use in the USA at $1.1 \%$ in 2017 , up from $0.5 \%$ in $2016 .{ }^{37}$ There is limited evidence, primarily around awareness, in Mexico and Guatemala. ${ }^{38} 39$ The particular popularity in Japan may be ascribed to ENDS being significantly restricted in that market. In the USA, IQOS has been authorised as a modified risk tobacco product under an exposure modification order. ${ }^{40} \mathrm{In}$ the EU, HTPs are regulated under the Tobacco Products Directive as a novel tobacco product.

\section{Oral tobacco products and oral nicotine products}

Nicotine can be delivered in non-combusted forms, and oral delivery has been a common method, including chewing tobacco and moist snuff as used in North America, Scandinavia, Asia and Africa. For purposes of this paper, we use oral tobacco products (OTP) to refer to products that contain cut tobacco leaf material (eg, snus) and oral nicotine products (ONP) for products that do not (eg, dissolvable tablets). Smokeless tobacco (ST) companies have attempted to expand their segment of the nicotine product market-OTPs targeted toward smokers. In 2001, Swedish Match launched Exalt ${ }^{41}$ and the US Smokeless Tobacco Company (USSTC) launched Revel, ${ }^{42}$ both portioned snus products to try to appeal to tobacco users who were not attracted to traditional smokeless tobacco. Seeing an opportunity, US cigarette companies began to either purchase smokeless tobacco companies or market their own smokeless products. In 2006, RJR purchased Conwood ${ }^{43}$ and also began to market Camel Snus. ${ }^{42}$ PM, leveraging the popularity of Marlboro cigarettes, launched Marlboro Snus, Marlboro Snuff and Taboka (another form of snus), ${ }^{42}$ before acquiring USSTC. Early ONPs also began to emerge at this time, including the 2001 launch of Ariva, a dissolvable pellet, followed by Stonewall, a larger dissolvable pellet targeted at ST users. Ariva and Stonewall left the market in $2012 .{ }^{44} \mathrm{PM}^{45}$ and $\mathrm{RJR}^{46}$ also ventured into this market with Camel orbs, strips and sticks (compressed dissolvable tobacco shaped and similar in size to a toothpick) launched in 2009 and withdrawn in 2013, Marlboro/Skoal sticks launched in 2011 and 
Revel (now Velo) nicotine lozenges in 2019. 47 'Tobacco-free' ONPs are re-emerging in the USA and Europe. ${ }^{48} 49$ Examples of these products include ZYN (Swedish Match), On! (Altria) and Velo (RJR Vapor), among others. In Europe, 46 brands have been identified, with 27 new brands of nicotine pouches launching in $2020 .^{50}$ These products appear to fall outside the EU ban on snus and the existing Tobacco Products Directive. German regulators ruled that they were not permitted to be sold in that country. Few studies have been published recently on these products, though one report suggests low use prevalence in the Netherlands $(<1 \%) .^{48}$ These products have also been marketed in Pakistan, Kenya and Tanzania, though data on uptake are not published. ${ }^{51}$ Pouches are not legal for sale in Australia (except by prescription) and are permitted in New Zealand.

\section{ADDICTIVENESS AND APPEAL OF ENDS, HTPS AND ONPS Nicotine delivery from ENDS, HTPs and ONPs}

Nicotine is a volatile chemical that is the most abundant tobacco alkaloid and the main addictive component of ENDS, HTPs and ONPs. Nicotine can be absorbed buccally, in the upper airways and in the lungs. ${ }^{52}$ When inhaled from ENDS and HTPs, nicotine is effectively absorbed in the lungs where it rapidly enters the pulmonary venous circulation, passes through the heart, enters arterial circulation and moves across the blood-brain barrier. Although nicotine absorption from ONP through buccal cell membranes is rapid, the rise in the brain nicotine level appears to be slower than with inhalable products. Once in the brain, nicotine binds to nicotinic acetylcholine receptors leading to the release of multiple neurotransmitters (dopamine, norepinephrine, serotonin, gamma aminobutyric acid (GABA), glutamate and endorphins) in the central nervous system. ${ }^{53}$ Dopamine is the predominant neurotransmitter released, and it is associated with pleasure and appetite suppression. The release of these neurotransmitters is critical in the reinforcing and dependenceproducing effects of nicotine. ${ }^{54}$

Inhaled ENDS and HTP emissions constitute an aerosol of liquid particles (liquid phase) suspended in air (gas phase). Design characteristics of ENDS and HTPs and user behaviours (such as puffing patterns) influence nicotine yield in an inhaled aerosol and its dose delivered to the user. For example, the nicotine yield in ENDS aerosols is determined by device power, nicotine concentration and type of solvent used. Although early generations of ENDS did not effectively deliver nicotine to users, newer generations were engineered and modified to produce more aerosol and a more consistent nicotine yield. ${ }^{55} 56$ Studies with newer ENDS have shown that those products can generate nicotine yields comparable to, and sometimes exceeding, the nicotine yield from one tobacco cigarette $(1.76-2.20 \mathrm{mg}) .^{57-59}$ Industry-funded studies on novel ONPs suggest that those products deliver nicotine as quickly and to a similar extent as existing smokeless products. ${ }^{6061}$

The $\mathrm{pH}$ of inhaled aerosol generated from ENDS and HTPs plays a large role in nicotine bioavailability. Buccal absorption of nicotine from ONPs is also highly dependent on $\mathrm{pH}$ of the saliva. Since nicotine is a weak base $(\mathrm{pKa}=8.0)$, at a higher $\mathrm{pH}$, a larger portion of nicotine is unprotonated ('free-base') and nicotine is more volatile. ${ }^{62}$ Because of higher $\mathrm{pH}$, a significant proportion of nicotine is present in the gas phase of inhaled aerosol. This leads to increased absorption in the oral cavity and upper respiratory tract but also causes more irritation and sensation of the unpleasant taste of nicotine. With lower $\mathrm{pH}$, more nicotine is present in the liquid phase of aerosol leading to limited absorption in the upper respiratory tract but also reducing harshness and unpleasant taste. This allows users to inhale deeply with less irritation ${ }^{63}$ resulting in an increased lung deposition of the aerosol and enhanced absorption of nicotine through the lungs. Pod-based ENDS devices that were introduced in mid2010s contain high concentrations of nicotine in its protonated form (nicotine salt liquid) which are lower in $\mathrm{pH}$ and consist of nicotine conjugated with a weak base (eg, benzoic acid, levulinic acid). ${ }^{64}$ The addition of acid in nicotine salts allowed manufacturers to greatly increase the concentration of nicotine while avoiding harshness and bitterness. ${ }^{65}$ For example, JUUL that contains 5\% nicotine salt solution was introduced in 2015 and has since become the most popular ENDS brand available in the USA. ${ }^{66}$ The availability of highly concentrated nicotine salt solutions seems to be an increasing market trend, as one recent report suggests that an online search showed more than 70 US ENDS brands containing more than $5 \%$ nicotine. ${ }^{67}$

\section{Consumer appeal of ENDS, HTPs and ONPs}

Despite decades of research and development, the sensory properties of cigarette alternatives are still generally rated lower than cigarettes by smokers. For example, while HTPs, to some extent, suppressed urges to smoke, ${ }^{68-70}$ their sensory properties and ease of use are generally rated lower than conventional cigarettes. ${ }^{20} 7172$ However, ENDS, HTPs and ONPs have common characteristics that may increase their appeal, particularly in high-income countries with well-established tobacco control programmes, including product regulation and public information about the risks of cigarette smoking. First, many newer products are perceived to have less severe risks than cigarettes, ${ }^{73}$ making them potentially attractive to health-concerned smokers. However, consumers may falsely believe that such claims mean products are risk free or that exposure reductions can be achieved without completely quitting smoking. ${ }^{74}$ Second, increasing restrictions on indoor use, sales, advertising and packaging have made cigarettes less attractive and convenient. For example, characterising flavours other than tobacco have been banned in cigarettes, but not in (most) other tobacco and nicotine products, in Europe, Canada and the USA. ${ }^{1975}$

While adults may use ENDS to quit or reduce smoking, ${ }^{73} 7677$ adolescents and young adults often mention novelty and curiosity. ${ }^{76-78}$ Flavours, in particular, attract both youth and adults to use ENDS ${ }^{7980}$; they decrease harm perceptions and increase willingness to try and initiate the use of ENDS. ${ }^{81}$ Other attractive elements include variety and choice of feature (design, nicotine levels, adjustable device settings, producing 'clouds'), packaging and price (especially relative to cigarettes), avoidance of smoking restrictions, positive sensory and other physical experiences, social acceptability and perceived safety for bystanders. ${ }^{76} 78-80$ Pod-style devices have become popular, especially among adolescents, with their attractive design, user-friendliness, less aversive vaping experiences, desirable flavours and discreetness. ${ }^{82}$

Many of these observations about ENDS carry over to HTPs. ${ }^{26} 29748384$ Common terms used in marketing or promotion of HTPs include 'reduced-risk', 'alternative', 'clean', 'smoke-free', 'innovative', 'chic' and 'pure'. ${ }^{72-86}$ HTPs are sold online and in concept stores (cf Apple stores) in high-end areas. ${ }^{87-91}$ HTPs in several markets are available in non-tobacco flavours. ${ }^{92} 93$ Other potentially attractive features of HTPs include less throat discomfort, appealing packaging, cleanliness, lack of ash and smoke and more social acceptability compared with smoking conventional cigarettes. ${ }^{72}$ Reported reasons to use HTPs are users' health concerns, costs, enjoyment and satisfaction, ease of use, use practices and social aspects. ${ }^{94} 95$ Overall, 
HTP's image is that of a high-demand, upscale product for techsavvy users, rather different from the image of cigarettes. ${ }^{90}$ The price of HTP tobacco inserts is similar to cigarettes, ${ }^{93}{ }^{96}$ and the device is expensive. ${ }^{90}$ Unlike cigarette packs (in markets where such labels are required), HTPs do not require graphic warning labels with explicit colour pictures as of yet. ${ }^{90}$

ONPs have emerged relatively more recently, primarily marketed online as non-combustible alternatives for tobacco and nicotine products..$^{98}$ Data on perceptions are limited, though a recent survey in the Netherlands showed that users perceived nicotine pouches as less harmful, but not less addictive than other tobacco and nicotine products, including cigarettes. $^{95}$ Nicotine pouches are available in fruit, mint and other flavours (eg, cinnamon and coffee), ${ }^{989}$ and they contain sweeteners. ${ }^{98}$ Further, the product is perceived as an effective method to quit smoking, and it is easy and discreet to use, particularly in places where smoking is banned. ${ }^{98}$ Reasons for use reported by ZYN users include reduced relative health risks, ease of use and discreteness. Concerningly, $40 \%$ of never users were 'curious to see what it was like. ${ }^{98}$ The costs of the product are slightly lower or comparable to a pack of cigarettes in the USA. ${ }^{99} 100$ ONPs have the potential to displace traditional smokeless tobacco products, such as in South Asia and Africa, where they are newly marketed. Indeed, ONPs now account for approximately $4 \%$ of the total smokeless tobacco market in the USA. ${ }^{101}$

\section{THE FUTURE OF TOBACCO AND NICOTINE PRODUCTS}

The major multinational tobacco companies have converged on the theme of harm reduction ${ }^{102-107}$; that is, moving away from combusted cigarettes and focusing on a 'smoke-free world'. ${ }^{104}$ Indeed, PMI established an ostensibly independent foundation to promote the idea ${ }^{108} 109$ (though this foundation appears to be less independent than claimed $^{110}$ ). Many leading tobacco companies have begun promoting ENDS, HTPs and ONPs that they claim to market toward smokers. ${ }^{102-107}$ Having learnt lessons from previously marketed products that were withdrawn, improving product appeal and expanding the market seem to be the companies' main priorities. ${ }^{102-107111}$ For example, BAT plans to release Vuse Zero, an ENDS product with zero nicotine, and a variety of new strengths, flavours and formats (pouch, lozenge) for their ONP, Velo. ${ }^{102}$ In addition, they are developing a carbon tip HTP that will be known as Neo Core. ${ }^{111}$ Similarly, PMI has four platforms of 'smoke-free' nicotine products encompassing both HTPs and ENDS designs. ${ }^{112}$ Platform 1 is battery powered and heated with a ceramic heating blade (eg, IQOS and Marlboro Heatsticks). ${ }^{112}$ PMI plans to expand their IQOS HTP product with the release of the IQOS ILUMA, an HTP product using Smartcore induction technology. ${ }^{104}$ Platform 2 is heated with charcoal and does not require a battery source (reminiscent of RJR's Eclipse product from the late 1990s), which is planned to be branded as TEEPS. ${ }^{112}$ The second two platforms are nicotine-containing ENDS that are battery powered and differ on the nicotine and heating source. ${ }^{112}$ Platform 3 uses a nicotine salt and an electronically controlled heater (cf STEEM product). ${ }^{111} 112$ On the other hand, platform 4 uses an e-liquid (presumably free base) and an electronically controlled MESH heater, which reportedly remains in constant contact with the liquid to provide more consistent flavour. ${ }^{112}$ The HTP-ENDS lines are beginning to blur as PMI promotes IQOS VEEV, an ENDS product. ${ }^{104} 113$ Though PMI is the least invested in the ONP product category, the PMI US subsidiary, Altria, did acquire the oral nicotine pouch, On!. ${ }^{114}$
In addition to improving products, some companies plan to expand their market coverage. Tobacco companies strategically target various countries and populations with the most successful product. For example, Imperial plans to focus on marketing closed vapour products (ie, prefilled) in the USA, open vapour products (ie, refillable) in the UK and HTPs in Germany. ${ }^{106}$ Meanwhile, Altria in the USA has marketed their HTPs, IQOS and Heatsticks within a number of US states. ${ }^{107}$ IQOS is currently the only HTP approved for sale on the US market. ${ }^{115}$ However, there is currently a lawsuit in the USA, as well as in Germany, against PMI filed by BAT. ${ }^{115}{ }^{116}$ Reynolds American, the US BAT subsidiary, claims that the heating technology used in IQOS is a patent infringement and is seeking an importation ban. ${ }^{115} 116$ They claim that PMI copied patented technology developed for BAT products, including Glo, Vuse Vibe and Vuse Solo. ${ }^{115} 116$ While the cases are ongoing, PMI argues that even if they are at fault, the USA should not exclude IQOS from the market because of the potential to reduce smoking. ${ }^{15} 116$

The role of explicit harm reduction claims in transitioning smokers to other forms of nicotine delivery is yet to be determined. In the USA, eight snus products sold by Swedish Match were the first tobacco products to be authorised as modified risk tobacco products (MRTP) ${ }^{117}$ IQOS with Marlboro Heatsticks achieved a similar designation in $2020,{ }^{40}$ and applications are pending for Camel Snus, Copenhagen moist snuff and Moonlight low-nicotine cigarettes in the USA. ${ }^{118}$ As yet, no ENDS or ONPs have publicly confirmed submitting MRTP applications. ONPs, in particular, present an interesting challenge as they resemble pharmaceutical nicotine replacement products (NRT) ${ }^{100}$ Superficially, oral nicotine lozenges may look like NRT lozenges, though they are often sold at higher concentrations $(8 \mathrm{mg}$ vs 4 $\mathrm{mg}$ ) and with more attractive flavouring, marketing and packaging (and lacking NRT's extensive labelling of potential side effects or instructions for use). This blurring of lines may present regulatory challenges around when a product constitutes a drug. The emergence of products claiming to use synthetic nicotine also presents important questions around public perception and its impact on the regulatory process. ${ }^{119} 120$

Policy developments may also intervene to shape the marketplace. For example, in April 2021, the Biden administration committed to removing menthol cigarettes (and cigars) from the US market and reintroduced plans to move forward a nicotine standard for cigarettes. This follows similar menthol bans in Canada, ${ }^{121-123}$ the EU and other countries. ${ }^{124}$ Characterising flavours other than menthol have been banned in cigarettes in the EU since 2016 and menthol was added in 2020. A recent report by the Joint Action Tobacco Control concludes that menthol facilitates inhalation. ${ }^{125}$ On this basis, some member states, such as Germany and Finland, currently prohibit use of menthol at any level (not just as a characterising flavour) based on its inhalation facilitating properties. Other tobacco products, such as cigars, cigarillos and snus, are exempt from this ban, though member states are increasingly banning flavours in ENDS. Menthol bans may shift smokers toward HTPs, ENDS or ONPs, particularly if such regulations do not apply to these products. Regulatory activities around new products have on occasion led to litigation-WHO in 2021 identified over 80 such cases. ${ }^{126}$ Overall, WHO notes that manufactures may challenge whether existing laws apply to their product; attempt to carve out, or have their products fall into, regulatory loopholes; and appeal to relative risk (compared with cigarettes) as a rationale to allow marketing. ${ }^{127}$ Products claiming to contain synthetic nicotine (as opposed to nicotine derived from tobacco) have emerged in the past 2-3 years, largely in response to specific 
regulatory decisions as to what constitutes a tobacco product (eg, US FDA). Depending on how the courts rule on such claims, this may present an ongoing challenge to regulation of nicotinecontaining products, and testing the provenance of nicotine may become a necessary part of the regulator's toolbox.

Just because cigarette smoking is declining in high-income countries, or among high-income and educated individuals within countries, it does not mean global tobacco control is finished-cultural, regional and socioeconomic differences in tobacco use must be considered. ENDS, HTPs and ONPs are marketed primarily in high-income countries, while tobacco products such as cigarettes remain heavily promoted in LMICs. ${ }^{128} 129$ An important question moving forward is the extent to which ENDS, HTPs or ONPs could be attractive to users of non-cigarette, combusted tobacco products (cigars, pipes, waterpipes, bidi, kretek) and users of traditional higher nitrosamine smokeless tobacco products. This is of particular interest in markets with high use of such products (eg, India, Indonesia, Eastern Mediterranean) where their use presents a significant population health risk. It is unclear which costs, appeal or regulatory structures would create barriers to the adoption of ENDS, HTPs or ONPs in LMICs. Different orientations to policy and reasoning-harm reduction versus precautionary principle-can also inform regulatory approaches. Advocates and regulators may have priority populations or specific areas of concern-smokers versus younger people; youth addiction versus adult chronic disease outcomes; cancer versus cardiovascular disease risks (which have different dose-response effects). One country, for example, may prioritise keeping novel products out of the marketplace to forestall the expansion of overall tobacco use, while another may lower barriers to entry as part of an overall strategy to reduce smoking specifically. In either case, mechanisms for removing specific products from the market if they prove problematic should be employed as a regulatory tool.

\section{KNOWLEDGE GAPS AND RECOMMENDATIONS FOR FUTURE RESEARCH}

A key question over the next decade is how best to study such a vast and evolving marketplace. Research on specific products to aid decision makers and regulators is lacking, and such research is also difficult to undertake as products continue to evolve in design, marketing and use. Data gathering and surveillance approaches need to evolve and adapt. Anticipation (ie, what product is 'the next JUUL'?) can benefit the field-the development of an early warning system, akin to structures used in drug abuse to identify misuse of medications, may be necessary. Engaging strategies used in marketing (eg, trend watching), surveillance of social media and search trend analysis also may prove valuable. ${ }^{130-132}$ More rapid surveillance is criticallarge, national surveys with cumbersome systems for adding or changing questions are too slow to provide timely data on an actively changing marketplace. This could be particularly challenging for LMICs with limited resources for surveillance or research, and an area for technical assistance from higher income countries, civil society or WHO.

Further, the questionnaires we use and how we conceptualise tobacco use are often derived from cigarettes (eg, smokeless tobacco and early ENDS dependence questionnaires were adapted from cigarette dependence measures). ${ }^{133}$ This may also need to change, as the use of new products may not be comparable-we see this already with ENDS that are puffed throughout the day rather than in discrete bouts. ${ }^{134}$ The growth of polytobacco use (ie, regular concurrent use of two or more tobacco products) further complicates studying product useasking about use behaviours for three products within a survey can be time consuming, but ignoring quantity and frequency of use of multiple products within individuals may present a misleading picture of tobacco use in the population. Established knowledge and methods for cigarettes often drive content and emissions research, so new toxicants can be missed (ie, we may not know what to look for). Thus, untargeted screening is needed to address products with potential for novel contents and emissions.

Finally, with the increasing integration of technology into the tobacco market (eg, heating and vaping devices that may have Bluetooth capabilities), the collaboration of tobacco regulators with regulators of other consumer goods, as well as consideration given to potential issues of data privacy and security, may be required. Understanding how a product uses technology to interact with the product user (eg, data gathering, retention and storage; location tracking and geofencing; product 'learning') would be important for regulators to understand.

\section{CONCLUSION}

The global market in tobacco is complex, changing and expanding. Even though many tobacco companies are looking to a 'reduced-harm' future by marketing alternative nicotine sources to smokers, that is not to say that these companies are giving up on the cigarette market. JTI states that they '... believe in the freedom of adults to choose' ${ }^{105}$ In addition, Imperial Tobacco, BAT and JTI have shown revenue growth with their cigarette brands and do not appear to have plans to move to a cigarette-free future as companies such as Altria, PMI and Swedish Match have explicitly claimed. ${ }^{102} 105106$ There is a fundamental need to study the impact of new and emerging products on population health in the context of different regulatory environments and across countries where the tobacco epidemic is at different stages. Full implementation of the Framework Convention on Tobacco Control (FCTC) and guarding against tobacco industry interference are important considerations.

\section{What this paper adds}

What is already known on this subject

- Over the past decade, noncigarette forms of nicotine delivery have emerged, including electronic nicotine delivery systems, heated tobacco products, and oral nicotine products.

- Certain products, especially ENDS, have gained popularity, concerningly among youth.

\section{What this paper adds}

- Differing regulatory regimes may place upward and downward pressures on use of both cigarettes and newer products, and may ultimately drive the extent to which cigarettes are displaced.

Contributors $\mathrm{RO}^{\prime} \mathrm{C}$ developed an initial outline and assembled the writing team. All authors contributed to the writing and editing of the manuscript and approved the final version.

Funding The authors have not declared a specific grant for this research from any funding agency in the public, commercial or not-for-profit sectors.

Competing interests None declared.

Patient consent for publication Not required.

Provenance and peer review Commissioned; externally peer reviewed. 
ORCID iDs

Richard O'Connor http://orcid.org/0000-0003-0644-182X

Liane M Schneller http://orcid.org/0000-0002-9575-2672

Nicholas J Felicione http://orcid.org/0000-0001-9034-3477

Maciej Lukasz Goniewicz http://orcid.org/0000-0001-6748-3068

David L Ashley http://orcid.org/0000-0002-1060-5893

\section{REFERENCES}

1 World Health Organization. Who global report on trends in prevalence of tobacco use 2000-2025, third edition. 3rd ed. Geneva: World Health Organization, 2019.

2 Reynolds American completes acquisition of Lorillard and related divestitures. PR Newswire.

3 Breland A, Soule E, Lopez A, et al. Electronic cigarettes: what are they and what do they do? Ann N Y Acad Sci 2017;1394:5-30

4 Esterl M. Got a Light-er Charger? Big Tobacco's Latest Buzz, 2012.

5 Levy D, Chaloupka F, Lindblom EN, et al. The US cigarette industry: an economic and marketing perspective. Tob Regul Sci 2019;5:156-68.

6 Levy DT, Lindblom EN, Sweanor DT, et al. An economic analysis of the Pre-Deeming us market for nicotine Vaping products. Tob Regul Sci 2019;5:169-81.

7 Esterl M. Altria to Launch MarkTen e-cigarette nationally. The Wall Street Journal 2014.

$8 \mathrm{JTI}$ acquires logic, the leading independent us e-cigarette company. agreement gives JT a global footprint in the e-cigarette market 2015.

9 Levy DT, Douglas CE, Sanchez-Romero LM, et al. An analysis of the FTC's attempt to stop the Altria-Juul Labs deal. Tob Regul Sci 2020;6:302-5.

10 Levy DT, Sweanor D, Sanchez-Romero LM, et al. Altria-Juul Labs deal: why did it occur and what does it mean for the US nicotine delivery product market. Tob Control 2020;29:e171-4.

11 Cornelius ME, Wang TW, Jamal A, et al. Tobacco Product Use Among Adults - United States, 2019. MMWR Morb Mortal Wkly Rep 2020;69:1736-42.

12 Kapan A, Stefanac S, Sandner I, et al. Use of electronic cigarettes in European populations: a narrative review. Int J Environ Res Public Health 2020;17. doi:10.3390/ijerph17061971. [Epub ahead of print: 1703 2020].

13 Zhao Z, Zhang M, Wu J, et al. E-Cigarette use among adults in China: findings from repeated cross-sectional surveys in 2015-16 and 2018-19. Lancet Public Health 2020:5:e639-49.

14 Agaku IT, Egbe CO, Ayo-Yusuf OA. Geospatial spread of e-cigarette vape shops in South Africa and the relationship with tobacco product use among adults. Health Place 2021;68:102507.

15 Agaku IT, Egbe CO, Ayo-Yusuf OA. E-Cigarette advertising exposure among South African adults in 2017: findings from a nationally representative cross-sectional survey. BMJ Open 2021;11:e048462.

16 Agaku I, Egbe CO, Ayo-Yusuf O. Associations between electronic cigarette use and quitting behaviours among South African adult smokers. Tob Control 2021 doi:10.1136/tobaccocontrol-2020-056102. [Epub ahead of print: 15 Jan 2021] (published Online First: 2021/01/17).

17 Gravely S, Driezen P, Ouimet J, et al. Prevalence of awareness, ever-use and current use of nicotine vaping products (NVPs) among adult current smokers and exsmokers in 14 countries with differing regulations on sales and marketing of NVPs: cross-sectional findings from the ITC project. Addiction 2019;114:1060-73.

18 WHO. Who reports progress in the fight against tobacco epidemic. Geneva, Switzerland:WHO, 2021

19 European Union. European tobacco products directive (EUTPD) (2014/40/EU), 2014 Available: https://eceuropaeu/health/sites/health/files/tobacco/docs/dir_201440_ enpdf

20 Simonavicius E, McNeill A, Shahab L, et al. Heat-not-burn tobacco products: a systematic literature review. Tob Control 2019;28:582-94.

21 Burrough B, Helyar J. Barbarians at the gate : the fall of RJR Nabisco.. In: 1St Collins hardcover. New York: HarperBusiness Essentials, 2008.

22 Pauly JL, Lee HJ, Hurley EL, et al. Glass fiber contamination of cigarette filters: an additional health risk to the smoker? Cancer Epidemiol Biomarkers Prev 1998:7:967-79.

23 Elias J, Dutra LM, St Helen G, et al. Revolution or redux? assessing IQOS through a precursor product. Tob Control 2018;27:s102-10.

24 Associated Press. Reynolds launching heat-not-burn cigarette, 2014.

25 Anti-Smoking body attacks smokeless cigarette device. Tob J int 2007

26 Caputi TL. Industry Watch: heat-not-burn tobacco products are about to reach their boiling point. Tob Control 2016;26:609-10.

27 Felberbaum M. Philip Morris Int'l to sell Marlboro HeatSticks. Salon, 2014.

28 Organization WH. Heated tobacco products (HTPS): market monitoring information sheet. Geneva: World Health Organization, 2018.

29 Bialous SA, Glantz SA. Heated tobacco products: another tobacco industry global strategy to slow progress in tobacco control. Tob Control 2018;27:s111-7.

30 Hori A, Tabuchi T, Kunugita N. Rapid increase in heated tobacco product (HTP) use from 2015 to 2019: from the Japan 'Society and New Tobacco' Internet Survey (JASTIS). Tob Control 2020. doi:10.1136/tobaccocontrol-2020-055652. [Epub ahead of print: 05 Jun 2020].
31 Lau YK, Okawa S, Meza R. Nicotine dependence of cigarette and heated tobacco users in Japan, 2019: a cross-sectional analysis of the JASTIS study. Tob Control 2021. [Epub ahead of print: 19 Mar 2021]. doi:10.1136/ tobaccocontrol-2020-056237

32 Odani S, Tabuchi T. Prevalence of heated tobacco product use in Japan: the 2020 JASTIS study. Tob Control 2021. doi:10.1136/tobaccocontrol-2020-056257. [Epub ahead of print: 11 Mar 2021]

$33 \mathrm{Kim} \mathrm{SH}$, Cho H-J. Prevalence and correlates of current use of heated tobacco products among a nationally representative sample of Korean adults: results from a cross-sectional study. Tob Induc Dis 2020;18:66

34 Gallus S, Lugo A, Liu X, et al. Use and awareness of heated tobacco products in Europe. J Epidemiol 2021. doi:10.2188/jea.JE20200248. [Epub ahead of print: 16 Jan 2021].

35 Gallus S, Borroni E, Liu X, et al. Electronic cigarette use among Italian smokers: patterns, settings, and adverse events. Tumori 2020:300891620915784.

36 Miller CR, Sutanto E, Smith DM, et al. Awareness, trial and use of heated tobacco products among adult cigarette smokers and e-cigarette users: findings from the 2018 ITC four country smoking and Vaping survey. Tob Control 2020. doi:10.1136/ tobaccocontrol-2020-055985. [Epub ahead of print: 29 Sep 2020].

37 Nyman AL, Weaver SR, Popova L, et al. Awareness and use of heated tobacco products among US adults, 2016-2017. Tob Control 2018;27:s55-61.

38 Cruz-Jiménez L, Barrientos-Gutiérrez I, Coutiño-Escamilla L, et al. Adult smokers' awareness and interest in trying heated tobacco products: perspectives from Mexico, where HTPs and e-cigarettes are banned. Int I Environ Res Public Health 2020;17:2173.

39 Gottschlich A, Mus S, Monzon JC, et al. Cross-Sectional study on the awareness, susceptibility and use of heated tobacco products among adolescents in Guatemala City, Guatemala. BMJ Open 2020;10:e039792.

40 FaD A. FDA Authorizes Marketing of IQOS Tobacco Heating System with 'Reduced Exposure' Information. Agency Will Closely Monitor Real-World Data to Assess if Marketing Continues to be Appropriate. Silver Spring, MD: Food and Drug Administration, 2020.

41 Swedish Match announces test market of Exalt - an alternative for smokers 2001.

42 Carpenter CM, Connolly GN, Ayo-Yusuf OA, et al. Developing smokeless tobacco products for smokers: an examination of tobacco industry documents. Tob Control 2009;18:54-9.

43 Postelnicu A. Reynolds buys Conwood for \$3.5bn. Financial Times, 2006

44 Star Scientific (STSI) to Discontinue Ariva, Stonewall Hard Snuff Production and Sales. Street Insider 20122012

45 LA-S Z. Altria smokeless tobacco sticks. CSP Daily News, 2011

46 Changes to camel ORBS (fresh) product for existing dissolvable markets. RJ Reynolds Tobacco 2009.

47 Brodwin E. Tobacco giant Reynolds just rolled out berry and cream nicotine lozenges as it faces new pressure from Juul for smokeless products. Business Insider 2019.

48 CGGM P, Bakker-'t Hart IME, Hegger I. Nicotineproducten zonder tabak voor recreatief gebruik Bilthoven. Netherlands: Rijksinstituut voor Volksgezondheid en Milieu (RIVM), 2021

49 Robichaud MO, Seidenberg AB, Byron MJ. Tobacco companies introduce 'tobaccofree' nicotine pouches. Tob Control 2020;29:e145-6.

50 Pouches T-FN. Snus): complete European market analysis report. Dublin, Ireland: Research and Markets, 2020

51 Tactics T. Nicotine pouches Bath, England: University of Bath, 2021

52 Benowitz NL, Hukkanen J, Jacob P. 3Rd. nicotine chemistry, metabolism, kinetics and biomarkers. Handb Exp Pharmacol 2009;192:29-60.

53 Benowitz NL. Pharmacology of nicotine: addiction, smoking-induced disease, and therapeutics. Annu Rev Pharmacol Toxicol 2009;49:57-71.

54 Benowitz NL. Nicotine addiction. N Engl J Med 2010;362:2295-303.

55 Farsalinos KE, Yannovits N, Sarri T, et al. Protocol proposal for, and evaluation of, consistency in nicotine delivery from the liquid to the aerosol of electronic cigarettes atomizers: regulatory implications. Addiction 2016;111:1069-76.

56 Goniewicz ML, Kuma T, Gawron M, et al. Nicotine levels in electronic cigarettes. Nicotine Tob Res 2013;15:158-66.

57 Wagener TL, Floyd EL, Stepanov I, et al. Have combustible cigarettes Met their match? the nicotine delivery profiles and harmful constituent exposures of second-generation and third-generation electronic cigarette users. Tob Control 2017:26:e23-8.

58 Havel CM, Benowitz NL, Jacob P, et al. An electronic cigarette Vaping machine for the characterization of aerosol delivery and composition. Nicotine Tob Res 2017;19:1224-31

59 El-Hellani A, Salman R, El-Hage R, et al. Nicotine and carbonyl emissions from popular electronic cigarette products: correlation to liquid composition and design characteristics. Nicotine Tob Res 2018:20:215-23.

60 Liu J, Wang J, Vansickel A, et al. Characterization of the abuse potential in adult smokers of a novel oral tobacco product relative to Combustible cigarettes and nicotine Polacrilex gum. Clin Pharmacol Drug Dev 2021;10:241-50.

61 Lunell E, Fagerström K, Hughes J, et al. Pharmacokinetic comparison of a novel Non-tobacco-Based nicotine pouch (ZYN) with conventional, Tobacco-Based Swedish Snus and American moist snuff. Nicotine Tob Res 2020;22:1757-63. 
62 Pankow JF. A consideration of the role of gas/particle partitioning in the deposition of nicotine and other tobacco smoke compounds in the respiratory tract. Chem Res Toxicol 2001;14:1465-81.

63 Leventhal AM, Madden DR, Peraza N, et al. Effect of exposure to e-cigarettes with salt vs Free-Base nicotine on the appeal and sensory experience of Vaping: a randomized clinical trial. JAMA Netw Open 2021;4:e2032757.

64 Goniewicz ML, Boykan R, Messina CR, et al. High exposure to nicotine among adolescents who use Juul and other vape pod systems ('pods'). Tob Control 2019;28:676-7.

65 Talih S, Salman R, El-Hage R, et al. Characteristics and toxicant emissions of JUUL electronic cigarettes. Tob Control 2019;28:678-80.

66 Huang J, Duan Z, Kwok J, et al. Vaping versus JUULing: how the extraordinary growth and marketing of JUUL transformed the US retail e-cigarette market. Tob Control 2019;28:146-51.

67 Jackler RK, Ramamurthi D. Nicotine arms race: JUUL and the high-nicotine product market. Tob Control 2019;28:623-8.

68 Haziza C, de La Bourdonnaye G, Merlet S, et al. Assessment of the reduction in levels of exposure to harmful and potentially harmful constituents in Japanese subjects using a novel tobacco heating system compared with conventional cigarettes and smoking abstinence: a randomized controlled study in confinement. Regul Toxicol Pharmacol 2016:81:489-99.

69 Haziza C, de La Bourdonnaye G, Skiada D, et al. Evaluation of the tobacco heating system 2.2. Part 8: 5-day randomized reduced exposure clinical study in Poland. Regul Toxicol Pharmacol 2016;81 Suppl 2:S139-50.

70 Lüdicke F, Picavet P, Baker G, et al. Effects of switching to the tobacco heating system 2.2 menthol, smoking abstinence, or continued cigarette smoking on biomarkers of exposure: a randomized, controlled, open-label, multicenter study in sequential confinement and ambulatory settings (Part 1). Nicotine Tob Res 2018;20:161-72

71 Lopez AA, Hiler M, Maloney S, et al. Expanding clinical laboratory tobacco product evaluation methods to loose-leaf tobacco vaporizers. Drug Alcohol Depend 2016:169:33-40.

72 Hair EC, Bennett M, Sheen E, et al. Examining perceptions about IQOS heated tobacco product: consumer studies in Japan and Switzerland. Tob Control 2018;27:s70-3.

73 Czoli CD, Fong GT, Mays D, et al. How do consumers perceive differences in risk across nicotine products? A review of relative risk perceptions across smokeless tobacco, e-cigarettes, nicotine replacement therapy and combustible cigarettes. Tob Control 2017;26:e49-58.

74 Glantz SA. Heated tobacco products: the example of IQOS. Tob Control 2018:27:s1-6.

75 Food and Drug Administration. Tobacco control act, 2009. Available: https:// wwwgovinfogov/content/pkg/PLAW-111 pub/31/pdf/PLAW-111 publ31pdf

76 Romijnders KAGJ, van Osch L, de Vries H, et al. Perceptions and reasons regarding ecigarette use among users and Non-Users: a narrative literature review. Int J Environ Res Public Health 2018;15. doi:10.3390/ijerph15061190. [Epub ahead of print: 06 06 2018].

77 Kinouani S, Leflot C, Vanderkam P, et al. Motivations for using electronic cigarettes in young adults: a systematic review. Subst Abus 2020;41:1-8.

78 European Union. Attitudes of Europeans towards tobacco and electronic cigarettes Special Eurobarometer 506, 2021.

79 Romijnders KA, Krüsemann EJ, Boesveldt S, et al. E-Liquid flavor preferences and individual factors related to Vaping: a survey among Dutch Never-Users, smokers, dual users, and exclusive Vapers. Int J Environ Res Public Health 2019;16. doi:10.3390/ijerph16234661. [Epub ahead of print: 2211 2019].

80 Laverty AA, Vardavas Cl, Filippidis FT. Design and marketing features influencing choice of e-cigarettes and tobacco in the EU. Eur J Public Health 2016;26:838-41.

81 Meernik C, Baker HM, Kowitt SD, et al. Impact of non-menthol flavours in e-cigarettes on perceptions and use: an updated systematic review. BMJ Open 2019;9:e031598

82 Fadus MC, Smith TT, Squeglia LM. The rise of e-cigarettes, pod mod devices, and JUUL among youth: factors influencing use, health implications, and downstream effects. Drug Alcohol Depend 2019;201:85-93.

83 Ratajczak A, Jankowski P, Strus P, et al. Heat not burn tobacco Product-A new global trend: impact of Heat-Not-Burn tobacco products on public health, a systematic review. Int J Environ Res Public Health 2020;17:409.

84 Bar-Zeev $Y$, Levine $H$, Rubinstein G, et al. IQOS point-of-sale marketing strategies in Israel: a pilot study. Isr J Health Policy Res 2019;8:11.

85 Staal YC, van de Nobelen S, Havermans A, et al. New tobacco and tobacco-related products: early detection of product development, marketing strategies, and consumer interest. JMIR Public Health Surveill 2018;4:e55.

86 Rosen LJ, Kislev S. IQOS campaign in Israel. Tob Control 2018;27:s78-81.

87 Tabuchi T, Kiyohara K, Hoshino T, et al. Awareness and use of electronic cigarettes and heat-not-burn tobacco products in Japan. Addiction 2016;111:706-13.

88 Liu X, Lugo A, Spizzichino L, et al. Heat-Not-Burn tobacco products are getting hot in Italy. J Epidemiol 2018;28:274-5.

89 Mathers A, Schwartz R, O'Connor S, et al. Marketing IQOS in a dark market. Tob Control 2019;28:237-8.
90 Kim M. Philip Morris international introduces new heat-not-burn product, IQOS, in South Korea. Tob Control 2018;27:e76-8.

91 Churchill V, Weaver SR, Spears CA, et al. IQOS debut in the USA: Philip Morris International's heated tobacco device introduced in Atlanta, Georgia. Tob Control 2020;29:e152-4.

92 Cho YJ, Thrasher JF. Flavour capsule heat-sticks for heated tobacco products. Tob Control 2019;28:e158-9

93 Lee J, Lee S. Korean-made heated tobacco product, 'lil'. Tob Control 2019;28:e156-7.

94 Tompkins CNE, Burnley A, McNeill A, et al. Factors that influence smokers' and exsmokers' use of IQOS: a qualitative study of IQOS users and ex-users in the UK. Tob Control 2021;30:16-23

95 Havermans A, Pennings J, Hegger I. Awareness, use and perceptions of cigarillos, heated tobacco products and nicotine pouches: a survey among Dutch adolescents and adults 2021.

96 Liber AC. Heated tobacco products and combusted cigarettes: comparing global prices and taxes. Tob Control 2019:28:689-91.

97 Keogh A. Nicotine pouches. Br Dent J 2021;230:61-2.

98 Plurphanswat N, Hughes JR, Fagerström K, et al. Initial information on a novel nicotine product. Am J Addict 2020;29:279-86.

99 Robichaud MO, Seidenberg AB, Byron MJ. Tobacco companies introduce 'tobaccofree' nicotine pouches. Tob Control 2020;29:e145-e146.

100 Kostygina G, England L, Ling P. New product marketing Blurs the line between nicotine replacement therapy and smokeless tobacco products. Am J Public Health 2016; 106:1219-22.

101 Delnevo CD, Hrywna M, Miller Lo EJ, et al. Examining market trends in smokeless tobacco sales in the United States: 2011-2019. Nicotine Tob Res 2021;23:1420-4.

102 Bowles JM T. Enterprise of the future: Transfortation and growth: bat, 2021. Available: https://www.bat.com/group/sites/uk_9d9kcy.nsf/vwPagesWebLive/ D06FKEVZ/\$FILE/medMDBYCMVH.pdf?openelement [Accessed 24 Mar 2021].

103 Swedish Match. Company presentation, 2021. Available: https://www. swedishmatch.com/globalassets/documents/presentations/2021 companypresentation_swedishmatch_en.pdf [Accessed 24 Mar 2021].

104 International PM. Pmi Investor day 2021. Available: https://philipmorrisinternational. gcs-web.com/static-files/21b7b3e0-49c2-4fc5-8c3c-b0f48220a53d [Accessed 24 Mar 2021]

105 Terabatake M. Buisness plan 2021: JT, 2021. Available: https://www.jt.com/ investors/results/forecast/pdf/2020/Full_Year/20210209_08.pdf [Accessed 24 Mar 2021].

106 Imperial Brands. Our transformation to unlock value, 2021. Available: https:// philipmorrisinternational.gcs-web.com/static-files/21b7b3e0-49c2-4fc5-8c3cb0f48220a53d [Accessed 24 Mar 2021].

107 Altria. Moving beyond smoking, 2021. Available: https://s25.q4cdn.com/ 409251670/files/doc_downloads/2021/02/2021-CAGNY-Presentation-FINAL-Slidesfor-Posting-FINAL.pdf [Accessed 24 Mar 2021].

108 Yach D. Foundation for a smoke-free world. Lancet 2017;390:1807-10.

109 van der Eijk Y, Bero LA, Malone RE. Philip Morris International-funded 'Foundation for a Smoke-Free World': analysing its claims of independence. Tob Control 2019;28:712-8

110 Cohen JE, Gilmore AB, Legg T. The foundation for a smoke-free World —even less independent from its tobacco company funder. Thebmjopinion 2021.

111 University of Bath. Next generation products: tobacco company brands, 2021. Available: https://tobaccotactics.org/wiki/next-generation-products-tobaccocompany-brands/ [Accessed 25 Mar 2021]

112 Philip Morris International. Our four smoke-free platforms PMI science. Available: https://www.pmiscience.com/our-products/our-four-platforms [Accessed 24 Mar 2021]

113 Philip Morris CR. Czech Republic Becomes First European Market to Launch IQOS VEEV: Philip Morris International's Most Advanced E-vapor Product To Date, 2020.

114 University of Bath. Cigarette companies investing in Snus, 2020. Available: https:// tobaccotactics.org/wiki/cigarette-companies-investing-in-snus/ [Accessed $25 \mathrm{Mar}$ 2021].

115 Gretler CD S. Philip Morris faces risk of U.S. Cigarette Alternative Block: Bloomberg, 2021. https://www.bloomberg.com/news/articles/2021-01-25/philip-morris-facesrisk-of-cigarette-alternative-block-in-u-s

116 Cavale S. Bat files patent suits against Philip Morris' IQOS products: Reuters, 2020 Available: https://www.reuters.com/article/us-britishamericantobacco-lawsuitphilip/bat-files-patent-suits-against-philip-morris-iqos-products-idUSKCN21R2MJ [Accessed 24 Mar 2021].

117 FaD A. Fda grants first-ever modified risk orders to eight smokeless tobacco products. FDA concludes completely switching from cigarettes to these authorized products lowers certain health risks. Silver Spring, MD: Food and Drug Administration, 2019.

118 Administration FaD. Modified risk tobacco products 2021. Available: https://www. fda.gov/tobacco-products/advertising-and-promotion/modified-risk-tobaccoproducts [Accessed 22 Feb 2021].

119 Jordt S-E. Synthetic nicotine has arrived. Tob Control 2021. doi:10.1136 tobaccocontrol-2021-056626. [Epub ahead of print: 07 Sep 2021] 
120 Gupta AK, Mehrotra R. Safety concerns for tobacco-free products containing synthetic nicotine. Nicotine Tob Res 2021;23:1980-1.

121 Chaiton M, Schwartz R, Shuldiner J, et al. Evaluating a real world ban on menthol cigarettes: an interrupted time-series analysis of sales. Nicotine Tob Res 2020;22:576-9.

122 Chung-Hall J, Fong GT, Meng G, et al. Evaluating the impact of menthol cigarette bans on cessation and smoking behaviours in Canada: longitudinal findings from the Canadian arm of the 2016-2018 ITC four country smoking and Vaping surveys. Tob Control 2021. doi:10.1136/tobaccocontrol-2020-056259. [Epub ahead of print: 05 Apr 2021].

123 Chaiton M, Schwartz R, Cohen JE, et al. Prior daily menthol smokers more likely to quit 2 years after a menthol ban than Non-menthol smokers: a population cohort study. Nicotine Tob Res 2021;23:1584-9. doi:10.1093/ntr/ntab042

124 Erinoso 0, Clegg Smith K, lacobelli M, et al. Global review of tobacco product flavour policies. Tob Control 2021:30:373-9.

125 RIVM B, ANSES N. ISS and the WP 9 independent review panel. WP9: D9.3 report on the peer review of the enhanced reporting information on priority additives. Joint Action on Tobacco Control 2020.

126 World Health Organization. Litigation relevant to regulation of novel and emerging nicotine and tobacco products: case summaries. Geneva, Switzerland: World Health Organization, 2021.

127 World Health Organization. Litigation relevant to regulation of novel and emerging nicotine and tobacco products: comparison across jurisdictions. Geneva, Switzerland: World Health Organization, 2021.
128 Campaign for Tobacco-Free Kids, American Cancer Society Cancer Action Network, American Heart Association, et al. Philip Morris Declares the "Year of Unsmoke," But Launches New Cigarette in Indonesia and Sells Over 700 Billion Cigarettes a Year Worldwide, 2019. Available: https://www.prnewswire.com/news-releases/philipmorris-declares-the-year-of-unsmoke-but-launches-new-cigarette-in-indonesia-andsells-over-700-billion-cigarettes-a-year-worldwide-300834886.html [Accessed $24 \mathrm{Mar}$ 2021].

129 University of Bath. Next generation products: Philip Morris international, 2021. Available: https://tobaccotactics.org/wiki/next-generation-products-philip-morrisinternational/ [Accessed 24 Mar 2021].

130 Ayers JW, Althouse BM, Allem J-P, et al. Revisiting the rise of electronic nicotine delivery systems using search query surveillance. Am J Prev Med 2016;50:e173-81

131 Ayers JW, Dredze M, Leas EC, et al. Next generation media monitoring: global coverage of electronic nicotine delivery systems (electronic cigarettes) on Bing Google and Twitter, 2013-2018. PLoS One 2018;13:e0205822.

132 Caputi TL, Leas E, Dredze M, et al. They're heating up: Internet search query trends reveal significant public interest in heat-not-burn tobacco products. PLoS One 2017:12:e0185735

133 Foulds J, Veldheer S, Yingst J, et al. Development of a questionnaire for assessing dependence on electronic cigarettes among a large sample of ex-smoking ecigarette users. Nicotine Tob Res 2015;17:186-92.

134 St Helen G, Ross KC, Dempsey DA, et al. Nicotine Delivery and Vaping Behavior During ad Libitum E-cigarette Access. Tob Regul Sci 2016;2:363-76. 